\title{
Experimental Study on Proportioning Optimized Ultra-Fine Aggregate Cementing Materials with Full Gold Tailings Using Response Surface Method
}

\author{
Jingyi LIU ${ }^{\mathrm{a}, 1}$, Zhenjun ZHOU ${ }^{\mathrm{b}}$, Zhihua SUN ${ }^{\mathrm{b}}$, Jiuran WEN ${ }^{\mathrm{b}}$ and Kaiping LIU ${ }^{\mathrm{b}}$ \\ ${ }^{a}$ Shaanxi Railway Engineering Vocational and Technical College, Weinan, China \\ ${ }^{\mathrm{b}}$ School of Materials Science and Engineering of Chang'an University, Xi'an, China
}

\begin{abstract}
In order to prepare the ultra-fine full gold tailing aggregate cementing materials, the gold tailing powders were mixed with cement under different proportions. Then the effect of sand quantity, water quantity and dosage of waterreducing agent on the compressive strength of the full tailing aggregate cementing materials was studied using response surface method in Design-Expert software. Based on the regression analysis of test results, a visual model was provided. The research results show that when the relative mass dosage of cement is 1 , the amount of sand is greater than 1.1, the amount of water is greater than 0.24 , and the amount of water reducing agent is 0.01 . The $7 \mathrm{~d}$ compressive strength of tailings concrete shows a significant negative linear correlation with the amount of sand and water. That implays the concrete strength decreases with the increase of the amount of sand and water. When the relative mass of cement is 1 , the maximum $7 \mathrm{~d}$ strength of concrete appears at the relative mass of sand 1.0 , the amount of water is 0.22 , and the amount of water reducer is 0.01 . The maximum $7 \mathrm{~d}$ compressive strength is about $75.43 \mathrm{MPa}$.
\end{abstract}

Keywords. Gold tailings, full tailing aggregate, cementing material, response surface method, strength test

\section{Introduction}

Concrete is one of the primary materials used in every construction. With the progress of China construction projects, the demand of concrete is growing day by day [1]. Sand and gravel aggregate are essential raw materials for preparing concrete. Overexploitation of sand and gravel aggregates over the years has caused not only visual pollution, noise pollution, water pollution, air dust pollution and solid waste pollution but also caused serious soil erosion, vegetation destruction and ecological environment deterioration [2-3]. For this reason, in accordance with the requirements of environmental protection, the exploitation of natural sand and gravel aggregates in many areas have been restricted. This issue has led to a sharp increase in the price of required aggregates in concrete projects and the cost of construction projects. There is a

\footnotetext{
${ }^{1}$ Jingyi Liu, Shaanxi Railway Engineering Vocational and Technical College, Weinan, China; E-mail: 306190545@qq.com.
} 
shortage of aggregates in many places, which affects the smooth progress of infrastructure projects [4].

Gold tailings are a kind of industrial waste produced by gold mine beneficiation processes. Many years of mining development have created an enormous number of tailings.

The accumulation of tailings not only causes waste of mineral resources and occupation of arable land, but also leads to environmental pollution, soil erosion and vegetation destruction. The tailings pond accident can simply cause natural disasters such as collapse, landslide and mudslide [5-8]. However, from the resources and environmental science perspective, gold tailings are a potential secondary resource. Therefore, the development and utilisation of tailings not only make rational use of mineral resources, but also solve the environmental and safety problems caused by tailings. If tailings sand can be used instead of natural sand and gravel as the aggregate in concrete, it can make up the gap of raw materials for concrete production and also turn waste into treasure. But up to now, there has not been a large-scale application of materials of this size as all aggregates of concrete in the concrete industry. Regression analysis is a statistical analysis method to determine the quantitative relationship between two or more variables. However, the classical regression analysis method can only processes the existing experimental data passively, and does not put any requirements on the arrangement of the experiment. There are few studies showed how the accuracy of the regression equation can be improved, so that the multi-factor experiment problem often fails to achieve the experimental purpose, also, sometimes it is impossible to test the suitability of the model [9]. A new optimisation method called the response surface method (RSM) can be applied to solve this problem. RSM, also known as the regression design method, is an optimisation method that is integrated by experimental design, regression analysis and other mathematical techniques. It actively collects data based on multiple linear regression to obtain a regression equation (response function) of better properties. This method can be used to establish continuous variable surface models, find out the quantitative relationship between test results and various factors, and evaluate the factors that affect the change process and their interactions, and determine the optimal level range. Because the multidimensional space surface, it builds closer to the actual situation, and the number of required test groups is relatively small, saving manpower and material resources. This method has been successfully applied to various engineering process optimisation [10].

In this paper, the RSM is used to carry out an experimental study on the strength of all tailings aggregate concrete. In the case that the relative mass of cement is 1 , the influence of sand, water and water reducer on the compressive strength of concrete is studied to provide a reference for the application of tailings sand as concrete aggregates.

\section{Design of Experiments}

\subsection{Materials}

A gold mine in Shaanxi, China produces the tailing sand used in the concrete as the flotation tailing sand. It is in the form of loose silt, with a specific surface area of 5.35 $\mathrm{m}^{2} / \mathrm{kg}$ and a density of $2.96 \mathrm{~g} / \mathrm{cm}^{3}$. The chemical composition was analysed by Shimadzu's LAB CENTER XRF-1800 X-ray fluorescence spectrometer, and the test results are shown in table 1. 
Table 1. Chemical composition of gold tailing/\%.

\begin{tabular}{cccccccccccc}
\hline $\mathrm{SiO}_{2}$ & $\mathrm{TiO}_{2}$ & $\mathrm{Al}_{2} \mathrm{O}_{3}$ & $\mathrm{Fe}_{2} \mathrm{O}_{3}$ & $\mathrm{MnO}$ & $\mathrm{MgO}$ & $\mathrm{CaO}$ & $\mathrm{Na}_{2} \mathrm{O}$ & $\mathrm{K}_{2} \mathrm{O}$ & $\mathrm{P}_{2} \mathrm{O}_{5}$ & LOI & TOTAL \\
\hline 68.76 & 0.43 & 13.59 & 2.99 & 0.06 & 1.42 & 3.13 & 2.48 & 3.35 & 0.23 & 3.01 & 99.45 \\
\hline
\end{tabular}

The D8 Advance X-ray diffractometer of the German Bruker Company was used to analyse the mineral composition of the tailing samples. The results are depicted in figure 1. It can be seen from figure 1, the main mineral components of gold tailings are quartz and feldspar. Refer to the national standard "GB/T14684-2011 Sand for Construction" to determine the particle gradation and fineness modulus of gold tailings. The screening results are presented in figure 2. After calculation, the fineness modulus of tailings sand is 0.58 , which does not meet the fineness requirement $(>0.7)$ of the national standard for construction sand superfine sand. Therefore, it can be concluded that tailings sand belongs to ultra-fine aggregate.

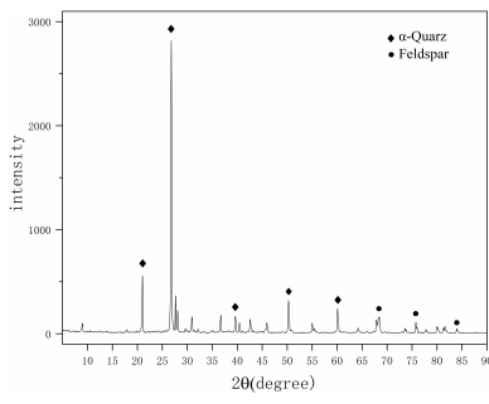

Figure 1. XRD pattern of gold tailing

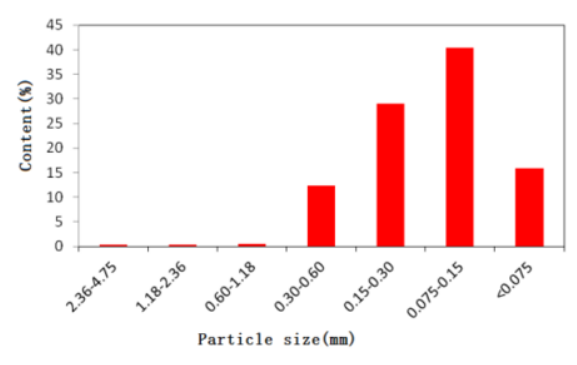

Figure 2. Particle size distribution of gold tailing.

The cement used is P.O.42.5 ordinary Portland cement produced by Shaanxi Shengwei Group Co., Ltd., and the quality meets the requirements of 'General Portland Cement Standard GB175-2008'. The considered water-reducing agent, is a commercially available high-efficiency polycarboxylic acid water-reducing agent PCE, with a solid content of $38.5 \%$, and the quality conforms to the 'Concrete Admixture GB8076-2008'. The water used is tap water.

\subsection{Methods}

According to the 'GB-T 50081-2019 Standard for Test Methods of Concrete Physical and Mechanical Properties', the gold tailings sand was used to carry out a non-coarse aggregate concrete preparation test for all aggregates. The RSM was conducted to analyse a $7 \mathrm{~d}$ compressive concrete strength, and to verify the experiment results.

\section{Results and Discussion}

\subsection{Initial Regression Orthogonal Design}

The purpose of the initial regression orthogonal test design is to find the steepest ascent direction of the strength extreme value and lay the foundation for the next rapid ascent test. The initial test examines the influence of sand-cement ratio $\left(\mathrm{x}_{1}\right)$, water-cement 
ratio $\left(\mathrm{x}_{2}\right)$ and water reducer $\left(\mathrm{x}_{3}\right)$ on the $7 \mathrm{~d}$ compressive strength of full tailings aggregate concrete.

Equations (1) indicates the relationship between $7 \mathrm{~d}$ compressive concrete strength $y$ and the sand-cement ratio $x 1$, the water-cement ratio $x 2$ and the water-cement ratio x3:

$$
y_{a}=\beta_{0}+\sum_{\mathrm{j}=1}^{3} \beta_{j} x_{a j}+\varepsilon_{a} \quad(a=1,2, \ldots, N)
$$

Where, $y_{a}$ is the $7 \mathrm{~d}$ compressive of the concrete strength in a test, $\mathrm{MPa} ; x_{a \mathrm{j}}$ is the independent variable, $\mathrm{j}=1 \sim 3$, which are the values of the sand-to-cement ratio, watercement ratio and the amount of water-reducing agent in a test; $\beta_{\mathrm{j}}$ is the independent variable coefficient, $\mathrm{j}=0 \sim 3$ to be determined. $\varepsilon_{a}$ is the random error of the ath trial, and it is assumed that it follows a normal distribution with a mean value of 0 and a variance of $\sigma^{2}$.

The orthogonal regression test uses the factor code value instead of the factor level value to perform the statistical analysis of the test results after the coding transformation, which significantly simplifies the statistical analysis. The coding of each factor $\mathrm{x}_{\mathrm{i}}$ in this article is represented by capital $\mathrm{X}_{\mathrm{i}}$. The codes and levels of research factors used in the experiment are shown in table 2 . In this table, $\Delta$ shows the interval changes in the test level. $\mathrm{L}_{8}\left(2^{7}\right)$ orthogonal table is used to arrange the test, the number of tests is $n=8$. Table 3 provides the test results.

Table 2. Factors and level coding for initial test.

\begin{tabular}{llll}
\hline Factor code & $\mathrm{x}_{1}$ & $\mathrm{x}_{2}$ & $\mathrm{X}_{3}$ \\
\hline-1 & 3.0 & 0.62 & 0.009 \\
0 & 2.9 & 0.61 & 0.010 \\
+1 & 2.8 & 0.60 & 0.011 \\
$\Delta$ & 0.1 & 0.01 & 0.001 \\
\hline
\end{tabular}

Table 3. Primary orthogonal test arrangement and result.

\begin{tabular}{lllll}
\hline No. & $\mathrm{X} 1$ & $\mathrm{X} 2$ & $\mathrm{X} 3$ & $\begin{array}{l}\text { Y (7d compressive strength, } \\
\mathrm{MPa})\end{array}$ \\
\hline 1 & -1 & -1 & -1 & 21.2 \\
2 & -1 & -1 & 1 & 20.9 \\
3 & -1 & 1 & -1 & 21.3 \\
4 & -1 & 1 & 1 & 21.4 \\
5 & 1 & -1 & -1 & 22.8 \\
6 & 1 & -1 & 1 & 23.2 \\
7 & 1 & 1 & -1 & 23.5 \\
8 & 1 & 1 & 1 & 23.6 \\
$\Sigma \mathrm{X}_{\mathrm{j}} \mathrm{y}_{\mathrm{j}}$ & 8.3 & 1.7 & 0.3 & \\
$\beta_{\mathrm{j}}=\Sigma \mathrm{X}_{\mathrm{j}} \mathrm{y}_{\mathrm{j}} / \mathrm{n}$ & 1.0375 & 0.2125 & 0.0375 & \\
\hline
\end{tabular}


Based on the experimental results presented in table 2, the analysis of variance of the initial mathematical model and the significance test of the regression coefficient was carried out. Table 4 illustrates the results.

Table 4. Significance test of primary regression results.

\begin{tabular}{|c|c|c|c|c|c|}
\hline \multicolumn{3}{|c|}{ Source of variation $S_{j}$, sum of squares $f_{j}$, Degree of freedom } & \multicolumn{2}{|c|}{$\mathrm{F}=\left(\mathrm{S}_{\mathrm{j}} / \mathrm{f}_{\mathrm{j}}\right) /\left(\mathrm{S}_{\text {rest }} / \mathrm{f}_{\text {rest }}\right)$} & \multirow{2}{*}{$\begin{array}{l}\text { Significance } \\
*\end{array}$} \\
\hline $\mathrm{X}_{1}$ & 8.61125 & 1 & 222.2258065 & $\mathrm{~F}_{0.05}(1,4)=7.709$ & \\
\hline $\mathrm{X}_{2}$ & 0.36125 & 1 & 9.322580645 & $\mathrm{~F}_{0.05}(1,4)=7.709$ & $*$ \\
\hline $\mathrm{X}_{3}$ & 0.01125 & 1 & 0.290322581 & $\mathrm{~F}_{0.05}(1,4)=7.709$ & \\
\hline return & 8.98375 & 3 & 77.27956989 & $\mathrm{~F}_{0.01}(3,4)=16.694$ & $* *$ \\
\hline rest & 0.155 & 4 & & & \\
\hline
\end{tabular}

From the results of the significance test, it can be seen that the linear regression equation is highly significant (significance level $\alpha=0.01$ ), the coefficients of $X_{1}$ and $X_{2}$ are both significant $(\alpha=0.05)$. In contrast, the coefficient of $X_{3}$ is not significant. Because the first-order regression orthogonal design is orthogonal and the coefficients of each factor are independent to each other, the variable $X_{3}$ has no significant effect and can be directly discarded in the model. The response function is obtained as a linear regression equation and can be expressedas follow:

$$
\mathrm{y}=22.2375+1.03755 \mathrm{X}_{1}+0.2125 \mathrm{X}_{2}
$$

\subsection{Steepest Ascent Method Test Design (Rapid Ascend Method)}

According to the regression equation (2), set the step length factor to -0.2 , and use the steepest ascent method for the second round of experiments. Since the amount of water-reducing agent $x_{3}$ has no significant effect, in this round of tests, $\mathrm{x}_{3}$ is fixed to 0.010 , and the sand-to-cement ratio $\left(\mathrm{x}_{1}\right)$ and water-cement ratio $\left(\mathrm{x}_{2}\right)$ are changed to study its effect on the $7 \mathrm{~d}$ strength of tailings sand concrete. The test design and test results are shown in table 5 .

Table 5. Climb-quickly methods test arrangements and results.

\begin{tabular}{llll}
\hline & $\mathrm{x}_{1}$ & $\mathrm{x}_{2}$ & $\mathrm{y}$ \\
\hline Original test & 3.0 & 0.62 & 21.2 \\
$\beta_{\mathrm{j}}$ & 1.0375 & 0.2125 & \\
Order/step factor & -0.2 & -0.2 & \\
& & & \\
1 & 2.79 & 0.58 & 21.4 \\
2 & 2.59 & 0.54 & 31.3 \\
3 & 2.38 & 0.49 & 37.9 \\
4 & 2.17 & 0.45 & 43.4 \\
5 & 1.96 & 0.41 & 51.8 \\
6 & 1.76 & 0.36 & 55.6 \\
7 & 1.55 & 0.32 & 58.7 \\
8 & 1.34 & 0.28 & 64.3 \\
9 & 1.13 & 0.24 & 67.4 \\
10 & 0.92 & 0.19 & 65.1 \\
\hline
\end{tabular}


In the first 9 tests; the concrete strength value increases when sand amount $x 1$ and water amount $x_{2}$ changes. According to the statistics analyses obtained from the first 9 test results, it can also be seen when the sand content $x 1$ is greater than 1.1 and the water content $x_{2}$ is greater than 0.24 , the $7 \mathrm{~d}$ strength of concrete has a significant negative linear correlation with the sand content $x_{1}$ and the water content $x_{2}$. The correlation coefficients are $\mathrm{R}_{1}=-0.987$ and $\mathrm{R}_{2}=-0.988$; which means as the amount of sand and water increases, the strength of concrete decreases.

Then the linear regression equation of concrete $7 \mathrm{~d}$ strength, sand amount $x 1$ and water amount $x 2$ when sand amount $x_{1}$ is greater than 1.1 and water amount $\mathrm{x} 2$ is greater than 0.24 can be calculated as below:

$$
y=101.8+28.6 x_{1}-269.9 x_{2}
$$

The calculated coefficient of determination is $\mathrm{R} 2=0.978$. After testing, the linear regression equation is highly significant, and the confidence probability is $>99 \%$.

\subsection{Quadratic Regression Orthogonal Rotation Combination Design}

The strength value of the 10th test in table 4 is reversed, and the straight bar graph of the change of the test strength value is shown in figure 3 . Therefore, we redesigned the experiment around the highest point $(1.13,0.24)$ of the experimental results in table 4 . Since the response function in the area near the highest point does not conform to the law of linear change, a quadratic design and regression test are planned. The design method of the quadratic regression orthogonal rotation combination is adopted. The regression equation model is:

$$
y_{a}=\beta_{0}+\sum_{j=1}^{2} \beta_{j} x_{a j}+\sum_{j=1}^{2} \beta_{i j} x_{a i} x_{a j}+\sum_{j=1}^{2} \beta_{j j} x_{a j}^{2}+\varepsilon_{a}(a=1,2, \ldots, N, i, j=1,2)
$$

The meaning of each variable was addressed before.

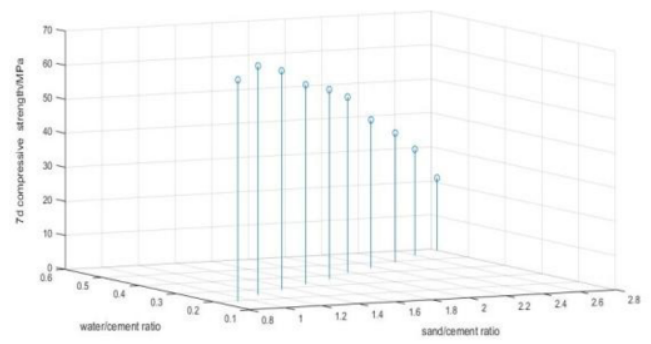

Figure 3. Straight bar graph of the relationship between $7 \mathrm{~d}$ compressive strength of concrete and sandcement ratio and water-cement ratio.

The codes and levels of research factors used in the test are shown in table 6 . In table $6, r$ is the radius of the test rotating sphere from the test centre point; $\Delta$ has the same meaning as before. Similar to a regression orthogonal experiment, after coding transformation, the factor code value is substituted for the factor level value to perform the test results' statistics. However, in the quadratic regression orthogonal rotation 
combination design, due to the correlation between the $X_{0}$ column and the $X_{j}^{2}$ column, to eliminate this correlation, this paper focuses on the square term $X_{j}^{2}$, as

$$
X \mathrm{a}_{\mathrm{j}}^{\prime}=X \mathrm{Xa}_{\mathrm{j}}^{2}-1 / \mathrm{n} * \Sigma \mathrm{Xa}_{\mathrm{j}}{ }^{2}
$$

Table 6. Factors and level coding for the third round of test.

\begin{tabular}{lllll}
\hline $\mathrm{x}_{\mathrm{j}}$ & $\mathrm{x}_{1}$ & $\mathrm{x}_{2}$ & Sand-to-cement ratio & Water-cement ratio \\
\hline$-\mathrm{r}$ & -1.414 & -1.414 & 0.79 & 0.19 \\
-1 & -1 & -1 & 0.85 & 0.20 \\
0 & 0 & 0 & 1.00 & 0.22 \\
+1 & 1 & 1 & 1.15 & 0.24 \\
$\mathrm{r}$ & 1.414 & 1.414 & 1.21 & 0.25 \\
$\Delta$ & 1 & 1 & 0.15 & 0.02 \\
\hline
\end{tabular}

The test arrangement and results are shown in table 7.

Table 7. Quadratic orthogonal rotation experiment design and test result.

\begin{tabular}{|c|c|c|c|c|c|c|c|c|c|}
\hline No. & $\mathrm{X}_{0}$ & $X_{1}$ & $\mathrm{X}_{2}$ & $\begin{array}{l}\text { Equivalent } \\
\text { sand }\end{array}$ & $\begin{array}{l}\text { Equivalent } \\
\text { water }\end{array}$ & $\mathrm{X}_{1} * \mathrm{X}_{2}$ & $\mathrm{X}_{1}{ }^{\prime}$ & $\mathrm{X}_{2}{ }^{\prime}$ & $\mathrm{Y}$ \\
\hline 1 & 1 & -1 & -1 & 0.85 & 0.20 & 1 & 0.385 & 0.385 & 66.8 \\
\hline 2 & 1 & -1 & 1 & 0.85 & 0.24 & -1 & 0.385 & 0.385 & 63.3 \\
\hline 3 & 1 & 1 & -1 & 1.15 & 0.20 & -1 & 0.385 & 0.385 & 64.1 \\
\hline 4 & 1 & 1 & 1 & 1.15 & 0.24 & 1 & 0.385 & 0.385 & 63.2 \\
\hline 5 & 1 & 1.414 & 0 & 1.21 & 0.22 & 0 & 1.385 & -0.615 & 63.9 \\
\hline 6 & 1 & -1.414 & 0 & 0.79 & 0.22 & 0 & 1.385 & -0.615 & 66.2 \\
\hline 7 & 1 & 0 & 1.414 & 1.00 & 0.25 & 0 & -0.615 & 1.385 & 65.3 \\
\hline 8 & 1 & 0 & -1.414 & 1.00 & 0.19 & 0 & -0.615 & 1.385 & 63.2 \\
\hline 9 & 1 & 0 & 0 & 1.00 & 0.22 & 0 & -0.615 & -0.615 & 69.7 \\
\hline 10 & 1 & 0 & 0 & 1.00 & 0.22 & 0 & -0.615 & -0.615 & 70.4 \\
\hline 11 & 1 & 0 & 0 & 1.00 & 0.22 & 0 & -0.615 & -0.615 & 69.7 \\
\hline 12 & 1 & 0 & 0 & 1.00 & 0.22 & 0 & -0.615 & -0.615 & 71.9 \\
\hline 13 & 1 & 0 & 0 & 1.00 & 0.22 & 0 & -0.615 & -0.615 & 70.3 \\
\hline bi & 72.33 & -0.057 & 0.921 & & & 0.65 & -2.292 & -2.744 & \\
\hline
\end{tabular}

After calculation and analysis, Equations (5) presents the preliminary regression:

$$
\mathrm{Y}=72.33-0.057 \mathrm{X}_{1}+0.921 \mathrm{X}_{2}+0.65 \mathrm{X}_{1} \mathrm{X}_{2}-2.292 \mathrm{X}_{1}^{\prime}-2.744 \mathrm{X}_{2}^{\prime}
$$

The results obtained from the analysis of variance are summarised in table 8 .

It can be seen from the results analysis of variance presented in table 8 , the regression equation has a significant impact, but the effects of $X_{1}, X_{2}$ and $X_{1} X_{2}$ are not significant. Therefore, discarding the $X_{1}, X_{2}$, and $X_{1} X_{2}$ terms from the initial regression equation (5) is changed to the following equation :

$$
\mathrm{Y}=72.33-2.292 \mathrm{X}_{1}{ }^{\prime}-2.744 \mathrm{X}_{2}{ }^{\prime}
$$

Restore the centralisation transformation to $X_{j}^{2}$, 


$$
\mathrm{Y}=75.43-2.292 \mathrm{X}_{1}^{2}-2.744 \mathrm{X}_{2}^{2}
$$

Table 8. Quadratic regression orthogonal rotation test design variance analysis table.

\begin{tabular}{lllllll}
\hline \multicolumn{2}{l}{ Source of variation $\mathrm{S}$} & \multicolumn{2}{l}{ Degree of freedom Mean square $\mathrm{F}$} & $\mathrm{F}_{0.05}$ & Significance \\
\hline $\mathrm{X}_{1}$ & 0.0256 & 1 & 0.0256 & 0.007 & 5.5914 & \\
$\mathrm{X}_{2}$ & 6.7885 & 1 & 6.7885 & 1.8608 & 5.5914 & \\
$\mathrm{X}_{1} \mathrm{X}_{2}$ & 1.69 & 1 & 1.69 & 0.4632 & 5.5914 & \\
$\mathrm{X}_{1}{ }^{\prime}$ & 37.1755 & 1 & 37.1755 & 10.1901 & 5.5914 & $*$ \\
$\mathrm{X}_{2}{ }^{\prime}$ & 53.291 & 1 & 53.291 & 14.6075 & 5.5914 & $*$ \\
return & 98.9706 & 5 & 19.7941 & 5.4257 & 3.9715 & $*$ \\
rest & 25.5371 & 7 & 3.6482 & & & \\
deviation & 3.24 & 4 & 0.81 & & & \\
Lack of fit & 22.2971 & 3 & 7.4324 & 2.0373 & 4.3468 & \\
\hline
\end{tabular}

Therefore: $\mathrm{S}_{\text {tatal }}=\mathrm{S}_{\text {return }}+\mathrm{S}_{\text {rest }}=98.9706+25.5371=124.5077$. The sum of variances of $X_{1}{ }^{\prime}$ and $X_{2}$ is $\mathrm{S}_{\mathrm{R}}=37.1755+53.291=90.4665$ decisive factor as $\mathrm{R}^{2}=\mathrm{S}_{\mathrm{R}} / \mathrm{S}$ 总 $=90.4665 / 124.5077=0.7266$, Correlation coefficient as $\mathrm{R}=0.8524$.

In the case of a significance level of 0.01 , the correlation coefficient's critical value is 0.7078 , so the confidence probability of the regression equation (7) is $>99 \%$.

Substituting $\mathrm{Xj}=\left(\mathrm{xj}_{\mathrm{j}}-\mathrm{xj}_{0}\right) / \Delta \mathrm{j}$ into equation $(7)$,

$$
y=75.43-2.292\left(\frac{x_{1}-1.0}{0.15}\right)^{2}-2.744\left(\frac{x_{2}-0.22}{0.02}\right)^{2}
$$

According to this, changing surface of concrete $7 \mathrm{~d}$ compressive strength and sand volume and water volume can be compared in figure 4. According to formula (8) and figure 4 , among the parameters studied, the maximum $7 \mathrm{~d}$ strength of concrete appears at $($ sand, water $)=(1.0,0.22)$, and the maximum strength is $75.43 \mathrm{MPa}$.

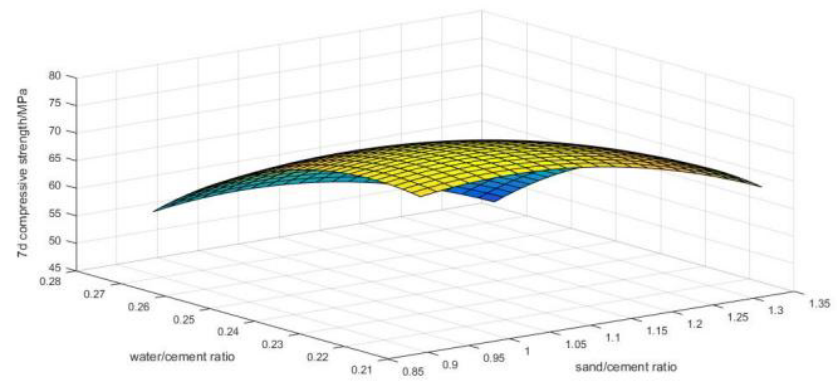

Figure 4. Variation of concrete strength with sand and water content at the top of the function. 


\subsection{Concrete Strength Verification Test}

Based on the 'GBT50080-2016 Standard for Test Methods for the Performance of Ordinary Concrete Mixtures' and 'GB-T 50081-2019 Standard for Test Methods for the Physical and Mechanical Properties of Concrete', the preparation test of all tailings aggregate concrete was carried out. The test ratio and three repetition results are shown in table 9 .

Table 9. Test ratio and result table.

\begin{tabular}{|c|c|c|c|c|c|c|c|c|c|}
\hline \multirow{2}{*}{ No. } & \multicolumn{4}{|c|}{ Raw material quality ratio } & \multirow{2}{*}{ Expansion ,mm } & \multicolumn{2}{|c|}{$\begin{array}{l}\text { Compressive } \\
\text { strength, } \\
\mathrm{MPa}\end{array}$} & \multicolumn{2}{|c|}{$\begin{array}{l}\text { Flexural } \\
\text { strength, } \\
\mathrm{MPa}\end{array}$} \\
\hline & cement & $\begin{array}{l}\text { Tailing } \\
\text { sand }\end{array}$ & Water & $\begin{array}{l}\text { Water- } \\
\text { reducing } \\
\text { agent }\end{array}$ & & $7 d$ & $28 \mathrm{~d}$ & $7 \mathrm{~d}$ & $28 \mathrm{~d}$ \\
\hline 1 & 1 & 1.0 & 0.22 & 0.01 & 180 & 73.8 & 82.6 & 11.9 & 13.4 \\
\hline 2 & 1 & 1.0 & 0.22 & 0.01 & 185 & 76.3 & 87.5 & 12.4 & 14.6 \\
\hline 3 & 1 & 1.0 & 0.22 & 0.01 & 182 & 74.6 & 83.7 & 12.6 & 13.8 \\
\hline average & 1 & 1.0 & 0.22 & 0.01 & 182 & 74.9 & 86.6 & 12.3 & 14.1 \\
\hline
\end{tabular}

It can be seen from table 9 , the $7 \mathrm{~d}$ average compressive strength value of tailings concrete obtained by repeated experiments is $74.9 \mathrm{MPa}$, which has only $0.7 \%$ error from the maximum strength value of $75.43 \mathrm{MPa}$ in the optimisation analysis. Good reproducibility.

\section{Results}

(1) When the relative mass amount of cement is 1, the sand amount is greater than 1.1, the water amount is greater than 0.24 , and the amount of water-reducing agent is 0.01 , the $7 \mathrm{~d}$ compressive strength of tailings concrete has a significant negative linear relationship with the amount of sand and water. It can be concluded that while the amount of sand and water increases, the strength of concrete decreases.

(2) When the relative mass of cement is 1 , the maximum $7 \mathrm{~d}$ strength of concrete appears at the relative mass of sand 1.0, the amount of water is 0.22 , and the amount of water reducer is 0.01 . The maximum $7 \mathrm{~d}$ compressive strength is about $75.43 \mathrm{MPa}$.

\section{Acknowladgements}

The authors appreciate the financial support from the Science and technology innovation talents service enterprise project from Xi 'an Science and Technology Bureau \& Xi 'an Finance Bureau (2020KJRC0125). 


\section{References}

[1] Guo RH, Hu JJ. Recycling and utilization of waste concrete. Sichuan Cement. 2019 Sep; (09): 282-283.

[2] UN. Sand and sustainability: Seek new solutions for the environmental governance of global sand resources. New York, UN: United Nations Environment Programme; 2019.

[3] Zhao YJ, Liu J, Yue MH, Ren JC. Geological environment management of sand pit after excessive mining of placer resources. Modern Mining. 2012, Jul; 27(07): 32-35.

[4] Hua DM, Liu X. Analysis on characteristics and application prospect of machine-made sand concrete. Development Guide to Building Materials. 2018, Aug; 16(12): 77-79.

[5] Ishihara K, Ueno K, Yamada S, Yasuda S, Yoneoka T. Breach of a tailings dam in the 2011 earthquake in Japan. Soil Dynamics and Earthquake Engineering. 2015, Nov; 68:3-22.

[6] Al TA, Leybourne MI, Maprani AC, MacQuarrie KT, Dalziel JA, Fox D, Yeats PA. Effects of acidsulfate weathering and cyanide-containing gold tailings on the transport and fate of mercury and other metals in Gossan Creek: Murray Brook mine, New Brunswick, Canada. Applied Geochemistry. 2006, Jun; 21: 1969-1985.

[7] Glotov VE, Chlachula J, Glotova LP, Edward L. Causes and environmental impact of the gold-tailings dam failure at Karamken, the Russian Far East. Engineering Geology. 2018, Sep; 245: 236-247.

[8] Wang Ch, Harbottle D, Liu QX, Xu ZhH. Current state of fine mineral tailings treatment: A critical review on theory and practice. Minerals Engineering. 2014, Apr; 58: 113-131.

[9] Wang T, Yan M, Guo HB. Application of response surface method (RSM), a new regression analysis method, in numerical simulation. Lithologic Reservoirs. 2011, Apr; 23(02): 31-36.

[10] Di JZh, Zhao W, Zhu ZhT, An WB, Ren YD. Treatment of response surface methodology to optimize enhanced coagulation process for micro-polluted water. Chinese Journal of Environmental Engineering. 2017 Jan; 11(1): 27-32. 